\title{
POSITIVE AND NEGATIVE ASPECTS OF HYPOTHALAMIC DISORDERS*
}

\author{
BY
}

\section{B. BROUWER $\uparrow$}

\section{Amsterdam}

In recent years I have collected with my coworkers at Amsterdam fifteen cases of hypothalamic disorders, which have been studied clinically and anatomically. Serial sections were made through the optic thalamus and the neighbouring parts of the brain and stained by various methods. The idea was to compare the results of experimental physiology with the clinico-pathological findings, especially with regard to the localization of syndromes in the hypothalamus.

The cases were all chronic. I have also studied clinically many acute cases, but such patients do not die when the lesions are small, and by the time they die the damage is usually so large that observations made on them do not lend themselves to scientific deductions.

It is a notable fact that in man lesions of the

* Lecture delivered at the University of Manchester on March 8, 1949.

+ It was with great regret that we learned of Professor Brouwer's death not long after we received this paper for publication.-ED. hypothalamus may be found without such clinical sequels as follow experimental lesions. Other authors, such as, for example, Riddoch, in England (1938), have already stressed this point. Thus there are positive and negative aspects in hypothalamic lesions (Brouwer, 1947), a fact that requires explanation.

In comparing some of our findings with the experimental data, I shall use in descriptions of the various nuclei the nomenclature of Le Gros Clark (1938).

\section{Diabetes Insipidus}

Much work has been done on this syndrome i experimental physiology. From the experiments of Broers (1932) in Holland and from those of Fisher and others (1938) in Chicago, we know that poly8 uria and polydipsia appear in dogs, cats, an monkeys after bilateral destruction of the suprac optic nuclei. Stimulation of these nuclei, as done by+

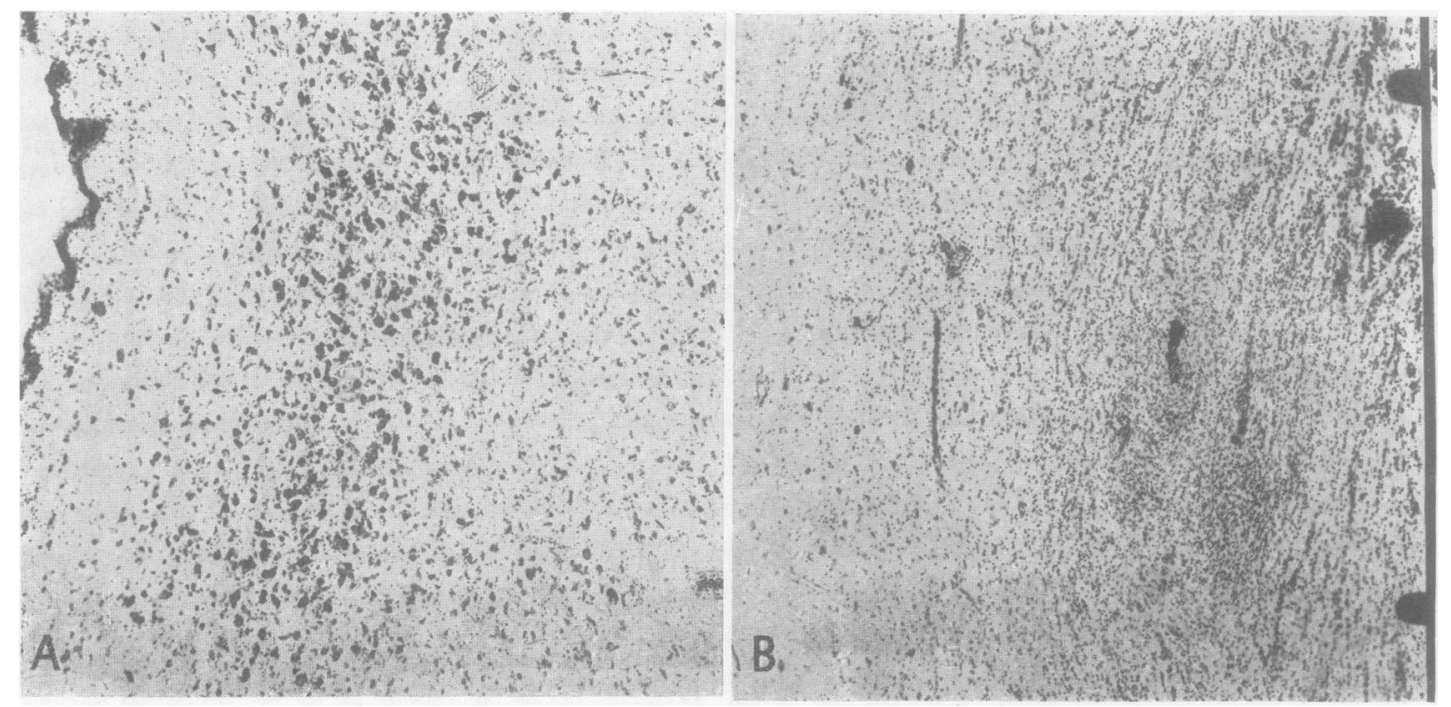

FIG. 1.-Supra-optical nucleus : (a) normal ; $(b)$ degenerated in diabetes insipidus. (Nissl preparation.) 
Hess (1948) in Zurich, and experimental irritation of the fibres connecting these nuclei with the neurohypophysis, as by Harris (1948) in Cambridge, causes a reduction of urinary excretion. In our series of fifteen cases we have four showing typical diabetes insipidus. In one of these the quantity of urine passed in twenty-four hours was 40 litres. The patient was of course very thirsty. In the evening two big glass bowls filled with water were placed at the bedside : next morning these were filled with urine. Injections with pituitrin reduced the excretion considerably. At the postmortem examination a chronic circumscribed encephalitis of the hypothalamus was found. The supra-optic nuclei had suffered severely (Fig. 1).

This was also the case in the three other observations of diabetes insipidus of our series. The second example was a carcinoma of the pineal body growing into the hypothalamus, and the third a localized chronic degeneration of various nuclei caused by a sarcoma of the cauda equina. In the fourth observation a tumour of the neurohypophysis and stalk extended into the hypothalamus. The supraoptic nuclei were intact in many of our cases in which no diabetes insipidus had been observed during life. But I have also seen two cases in which these nuclei were destroyed on both sides and yet no symptoms of polyuria and polydipsia had been present. On the other hand Roussy and others (1946) in France published two cases of polyuria and polydipsia in which no alterations in the hypophysis and the hypothalamus were found. We may conclude from these facts that the relations regarding this syndrome in man are more complicated than could be inferred from the experimental data.

\section{Glycosuria}

Hyperglycæmia and glycosuria are frequently seen after puncture in the tuberal region of animals, and several authors assume that lesions of the paraventricular nuclei are responsible for this syndrome. These symptoms disappear, however, after some days. This is true also in the acute phase of damage in man; for example, in traumatic lesions of the base of the skull and brain, or in spontaneous hæmorrhages caused by an aneurysm of one of the basal arteries. Long (1940), who recently analysed the various experimental results, concluded that up to the present there is little evidence to suggest that the control of the blood glucose level is permanently altered by hypothalamic lesions. In my experience glycosuria in chronic hypothalamic affections is very rare. It is true that glycosuria is often found in acromegaly. Here, however, it is not caused by - pressure on the hypothalamic nuclei, as is often said, but by the excessive secretion of the diabetogenic hormone. In our series only one case showed intermittent glycosuria. In this case there was a congenital malformation in the infundibular region and the tuber cinereum was composed almost exclusively of neuroglia. The shape of the paraventricular nuclei was altered and the number of cells was diminished. Several of our cases

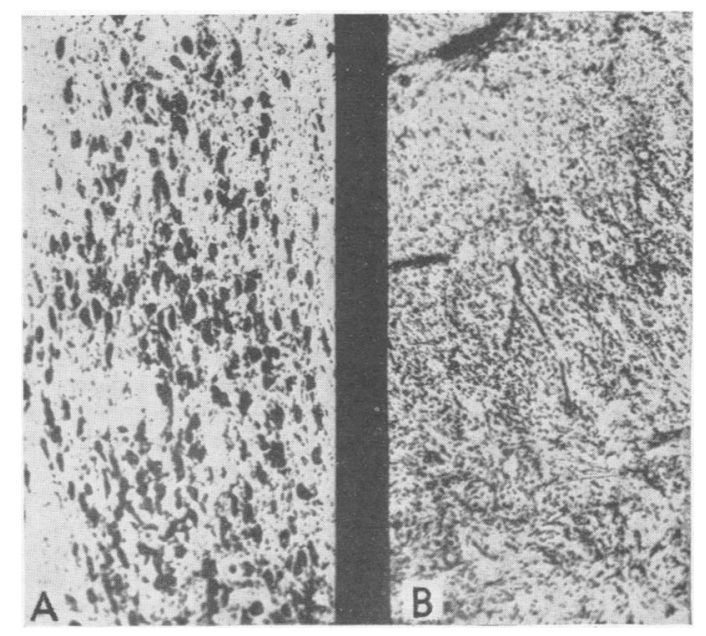

FIG. 2.-Paraventricular nucleus : (a) normal ; (b) degenerated, without glycosuria. (Nissl preparation.)

showed serious damage of the paraventricular nuclei although no glycosuria had been present (Fig. 2). I once observed severe diabetes mellitus in a man suffering from a tumour of the brain. The post-mortem examination showed that the hypothalamic region was destroyed by a glioma, but there were two diseases here not mutually connected, for the mother and one of the sisters of this patient were also diabetic. It was an example of the hereditary familial type of this disease. I know that some investigators described degenerations in the hypothalamic region in diabetes, but I must confess to being sceptical about the conception of a real extra-insular cerebral diabetes mellitus.

\section{Disturbances of Fat Metabolism and of the Genital Organs}

Experimental and clinical experience has shown that adiposity caused by a dysfunction of the hypophysis is less intensive than in hypothalamic lesions. Adiposity was seen in five cases of our series, of which two showed the syndrome of dystrophia adiposo-genitalis of Babinski-Fröhlich. In two observations sexual disorders were seen without adiposity or genital atrophy. Once I saw extreme 


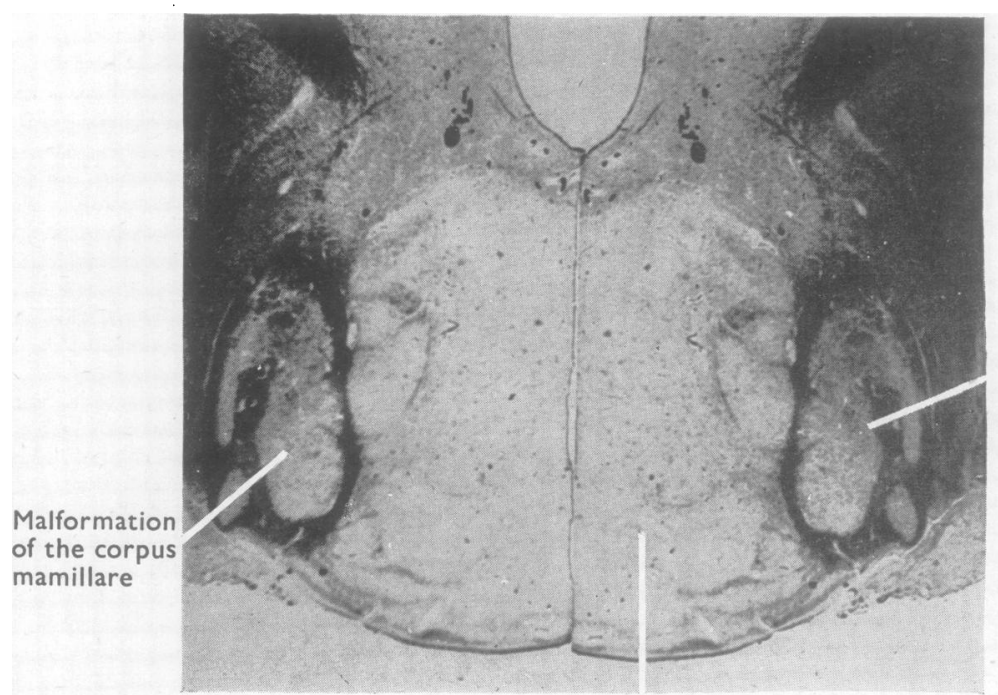

Malformation

of the tuber

cinereum
Malformation of the corpus

mamillare

Fig. 3.-Malformation in the hypothalamus associated with pubertas præcox. (Staining after Weigert-Pal.)

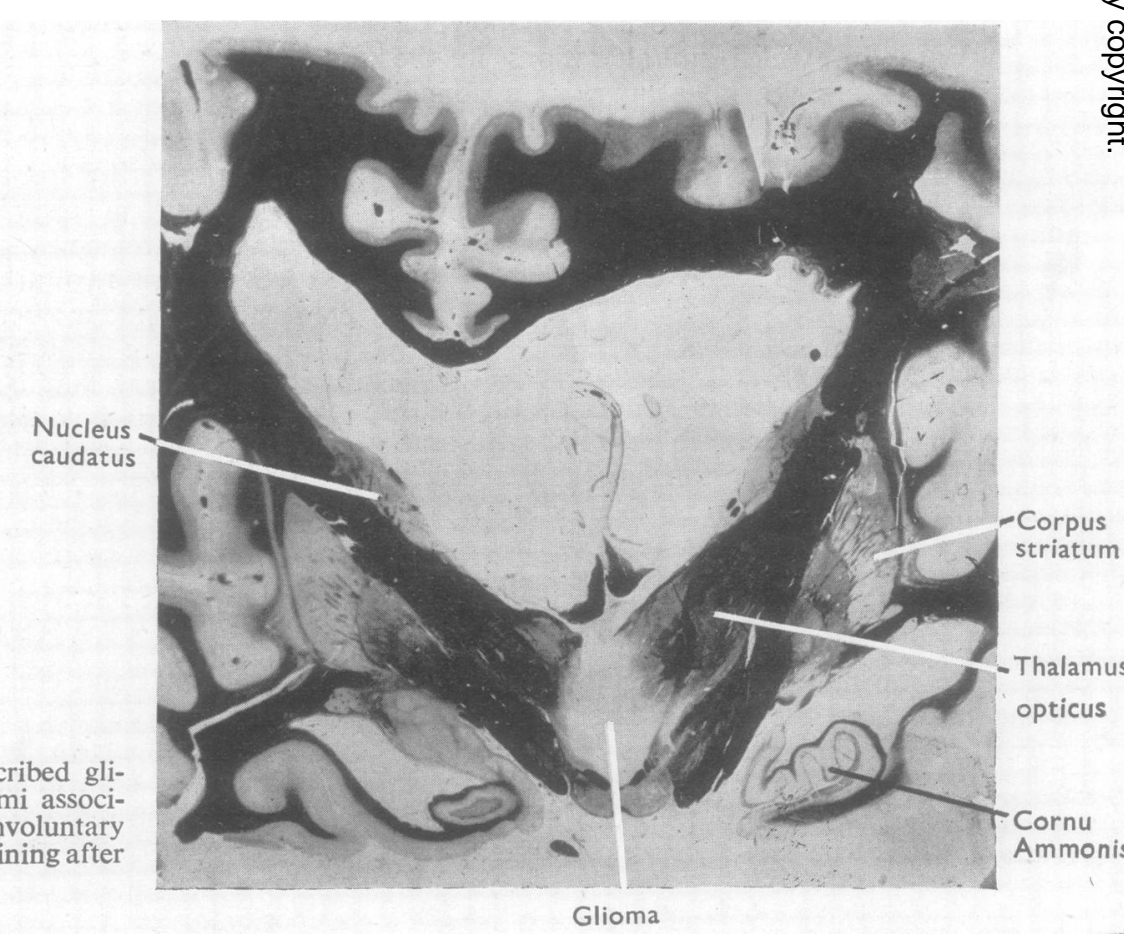

FIG. 4.-Circumscribed glioma hypothalami associated with involuntary micturition.(Staining after Weigert-Pal.)

Glioma 
loss of fat with emaciation. In this case degeneration was seen in several nuclei of the hypothalamus, amongst others in the dorso-medial and ventromedial hypothalamic nuclei, in the ventro-lateral nuclei, and in the anterior part of the nucleus hypothalamicus posterior. Insufficient is yet known about where in the tuber cinereum disturbances of fat metabolism originate. Brobeck (1946) recently summarized our knowledge in this respect and amongst others referred to the work of Hetherington. $\mathrm{He}$ found that in the rat adiposity may be evoked more easily by making lesions in the ventro-medial and ventro-lateral hypothalamic nuclei, but also by destruction of the posterior part of the hypothalamus. Extensive lesions in the dorsal and the more oral areas did not cause such disturbances. Bustamente (1942) produced atrophy of the genital organs in the rabbit without adiposity by lesions in the posterior part of the tuber. Destruction of the mamillary bodies did not give these results.

From a study of the literature and from my personal experience it may be concluded that under special circumstances degeneration of the grey substance surrounding the infundibulum may evoke adiposity, or genital atrophy, or both together. It is striking that in two patients of our series the hypothalamus was seriously damaged but disturbances in fat metabolism or in the reproductive organs did not occur.

The relationship between pubertas præcox and the hypothalamus is of great interest. This syndrome is seen in tumours of the adrenal glands, the testes, and the pineal gland, and in hypothalamic affections. According to Marburg's conception the pineal body has an inhibitory influence on the development of the sexual organs. Experimental physiology has not supported this theory. Krabbe (1912) held the opposite view, arguing that the pineal tumours which give rise to the syndrome of pubertas præcox are teratomas secreting gonadotrophic substances, while other types of pineal tumours in young people are not accompanied by this syndrome. On the other hand an increasing number of descriptions of hypothalamic lesions causing macrogenitosomia are appearing in medical literature. The most striking example was that of Driggs and Spatz (1939), in which a hyperplastic malformation in the tuber cinereum was found.

The syndrome of pubertas præcox was seen twice in our series. The first patient (Brouwer and Brummelkamp, 1948) was an epileptic who at the age of seven had to be shaved and had some growth of pubic hair. A year later his external sexual organs were much too large for his age, and adiposity had developed. A circumscribed malformation of the tuber cinereum and hypoplastic mamillary bodies were found (Fig. 3). In the second case, the typical picture of pubertas præcox developed at the age of ten. This boy showed homosexual tendencies. At the post-mortem examination an astrocytoma in the hypothalamus was found penetrating the medial part of the right neothalamus. Many cells in the tuber cinereum had been destroyed but the mamillary bodies were intact (de Lange, 1943). In both cases there was no tumour in the pineal gland, the adrenal glands, or the testes; hence they are examples of the hypothalamic type of pubertas præcox. These examples suggest that it is the tuber cinereum from which this syndrome originates.

\section{Rarer Signs of Chronic Hypothalamic Affections in Man}

I shall now turn to some of the rarer symptoms and signs of chronic hypothalamic affections in man, and shall also discuss the relations between mental disorders and the hypothalamus. The experiments of Karplus and Kreidl have shown that the hypothala-

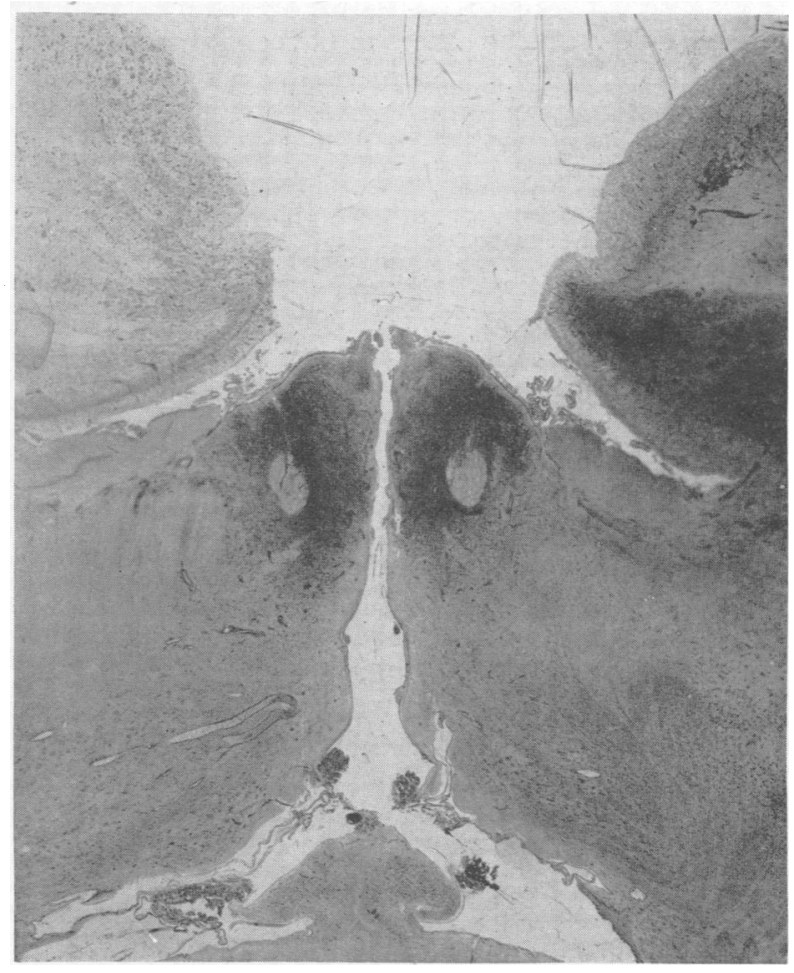

FIG. 5.-Chronic encephalitis in the hypothalamus associated with hyperthermia. (Nissl preparation.) 
mus exercises an influence on the movements of the bladder and the intestines. This was confirmed by Hess and Brügger (1943), among others, who induced in the cat excretion of urine, or defæcation, or both together, by electrical stimulation with weak currents of this region of the brain. I have seen this symptom twice in hypothalamic lesions, once in a case of chronic encephalitis, and once in a circumscribed glioma (Fig. 4). In the latter involuntary micturition was one of the first symptoms of this disease. We have to accept that the so-called " centres" for the movements of the bladder and the intestines are scattered over a considerable part of the hypothalamus.

As clinicians we know that surgical manipulations on the walls of the third ventricle often cause hyper. thermia. The central regulation of body temperature has been carefully analysed in experimental physiology by many investigators, amongst others by Thauer (1939), Ranson (1940), and Beattie (1938). Disorders of this function are most pronounced in animals after large bilateral destruction of the hypothalamus, by which the descending pathways to the tegmentum and the lower parts of the central nervous system are destroyed. The existence of such descending tracts is shown by Beattie and others (1930). Disturbances in the central thermoregulation in chronic conditions in man are rare. We have seen these, however, in a patient who had fever for a long period. Pathological changes in the internal organs such as could have explained this fever were not found either on clinical examination or at post-mortem investigation. There was a chronic encephalitis which had not only altered the cells and fibres in the tuber cinereum (Fig. 5) and the mammillary bodies, but which extended to the grey substance of the walls of the third ventricle and reached the preoptic area. It is probable that the hyperthermia in this case was caused by irritation. This patient also suffered from attacks of hyperhydrosis on the left side of the body, while the encephalitis was more extensive on the right side. Furthermore he showed the typical left-sided facial tic of psychasthenic individuals. In a later stage of his illness these involuntary quick movements spread to his neck and arms. The experimental work of Hess (1948) has shown that by electrical stimulation of the hypothalamus contractions could be evoked in the muscles of the head, the trunk, and the extremities. Hess considers the hypothalamus to be an important area of co-ordination between the somatic and vegetative central nervous systems. Such reactions of the muscles as this patient showed may be the result of the influence which the hypothalamus exerts on the pallium.

In one of our observations we have seen amblyopia and concentric depression of the field of vision, like those found in hysterical individuals. One man showed in the retina of the left eye myopic changes which must have existed for long. The patient, however, made no complaints about depressed vision until the last years before his entrance into the clinic. He often saw a cloud in front of his left eye. The vision on the right side was normal during the first month of observation, but gradually dropped to $\frac{1}{4}$, and the field of vision narrowed. Anatomical examination showed that encephalitis had spared the optic nerves, the chiasma, and the optic tracts. This observation gains significance in connexion with investigations recently made in Switzerland. Francechetti (1944), for example, concluded from his observations that concentric depression of the field of vision may be the consequence of a lesion in the diencephalic-mesencephalic region of the brain outside the optic pathways. He founded this opinion on the experimental results of Hess (1943), who induced diminution of vision by circumscribed lesions in the hypothalamus, in which the optic fibres were not affected. Hess believes that the hypothalamus has an indirect inductive influence on the power of the optic system by the hypothalamo fugal fibres to the retina.

Since von Economo wrote his famous paper abouf disorders of the sleep mechanism in acute encepha litis, many articles have been published about tho hypothalamus and centres for the organization of sleep. Hess evoked sleep in the cat by electrica? stimulation of the hypothalamus, but several in vestigators could not confirm this. From a persona communication from Professor Hess it seems that real sleep in these animals follows only after stimulation of the lowest part of the massa intermedia, about $3 \mathrm{~mm}$. lateral to the middle line. This area does not belong however to the real hypothalamus, but to the neothalamus. In our observations of chronic patients we have not seen severe attacks of sleep, and only twice have we observed slight disorders of sleep, one of which showed inversion of the sleep mechanism : the patient slept during the day and was awake and agitated at night.

In the literature on experimental physiology there is a difference of opinion about the influence of the hypothalamus on the growth of young animals. Aschner (1929) has always insisted that by compression or damage of the hypothalamus in young animals dwarfism may be induced, but many others ascribe this to a lesion of the hypophysis. Most cases of nanism reported in the literature are caused by pure hypophyseal affections or by craniopharyngeomata in which this gland and the hypo- $\sigma$ thalamus suffer together. An interesting form of $N$ dwarfism is the so-called progeria of Gilford, in $\underset{\mathcal{E}}{N}$ 
which the retardation of growth is combined with loss of all the hairs of the head, while the patients furthermore give the impression of being much older than their real age. Manschot (1940) in Amsterdam found diminution of the number of eosinophil cells in the hypophysis in such a case. I have examined serial sections of the optic thalamus in a similar case and found only slight hydrocephalus, the nuclei in the hypothalamus being intact. However Goldstein (1928) and later Gagel (1936) published examples of nanism in tumours of the hypothalamus, while the hypophysis was intact. Once I have seen retardation of growth in a young girl with toxic degeneration of several cell groups in the hypothalamus. Microscopic examination of the hypophysis did not show pathological alterations.

Increase or acceleration of growth, such as follow injection of hypophyseal extracts, has not yet been found in experiments on the hypothalamus. In acromegaly an eosinophil adenoma of the hypophysis is not always present. Carnot and his coworkers found a tumour of the left frontal lobe in such a case, while the hypophysis was microscopically intact. Cushing showed that acromegalic symptoms may occur in tumours of the brain of various localization, and that these symptoms disappear after removal of the tumour. It is suggested that they are caused by irritation of the cells in the hypothalamus in consequence of the increased amount of cerebrospinal fluid in the third ventricle. Several examples of encephalitis of this region with acromegalic symptoms have been published. My personal experience has taught me to be very cautious in this matter. In 1919 I saw a young woman suffering from acute encephalitis of von Economo. After some time two neurological diseases developed : typical Parkinsonism, and also acromegaly. It seemed to be an example of the cerebral form of this last disease, but twenty-one years later post-mortem examination revealed an ordinary eosinophil adenoma of the hypophysis; in the brain I found degeneration of various cell groups in the substantia nigra and in the striate bodies, but the hypothalamus was normal. On the other hand I have once seen an acromegalic woman for whom I ordered radiotherapy. Many years later I examined the brain ; there was no adenoma, but an aneurysm of one of the basal arteries, pressing on the hypothalamus (Fig. 6).

\section{Relation between Mental Disorders and the Pathology of the Hypothalamus}

The experiments of Bard stimulated clinicians to analyse the emotional states of their patients. Bard evoked "sham rage" and other emotional disturbances in cats after extirpation of the telen- cephalon, the striate bodies, and the anterior part of the hypothalamus. These symptoms disappeared after removal of the caudal part of this region of the brain. In 1932 I saw several of these animals at Boston, and they made a great impression on me. For a survey of the mental disorders caused by affections of the hypothalamus, reference should be made to the recent publications of Alpers (1940) and Lhermitte and others (1942). In our series six cases showed severe mental disturbances; four belonged to the syndrome of Korsakoff with disorientation in space, time, and personality, difficulty in memorizing, and confabulation (Figs. 7 and 8). Our material is not unfavourable to Gamper's (1928) concept, that disease of the mammillary bodies and their surroundings has something to do with this syndrome. There is, however, no conclusive evidence, because this syndrome is also frequently seen in other pathological localizations in the brain. The mammillary bodies are association-centres and are connected with many other parts of the brain; hence it is probable that they form an important point of junction in the cerebral chain reflexes, which underlie psychical functions.

\section{Conclusions}

Finally I must compare the effects of chronic hypothalamic affections in man with experimental results. Our material illustrates the great variety in the clinical picture. These variabilities are caused (a) by differences in the localization and extent of the pathological process, $(b)$ by their nature and the tempo of their development, and (c) by the age of the patient. Accompanying disturbances in the brain outside the hypothalamus may also play a role.

Clinico-anatomical observations seldom offer opportunities to connect functional disturbances with the damage of special hypothalamic nuclei. Hence the task of the clinician regarding the problem of functional localization is more difficult than that of the physiologist. Clinical observations may, however, increase our insight into these relations provided that they are carefully controlled by microscopical investigation. In comparing experimental results with those of clinico-pathology one has to realize that the functional disorders that occur after experiments on animals are caused by acute lesions, in which the chains of neurones are suddenly interrupted. Our observations in man, however, were on cases in which the pathological process developed slowly from the onset, so that compensation by other parts of the central nervous system might take place. Today the best experimentally analysed syndrome is diabetes insipidus, but, we have seen that in man bilateral destruction of the supra- 


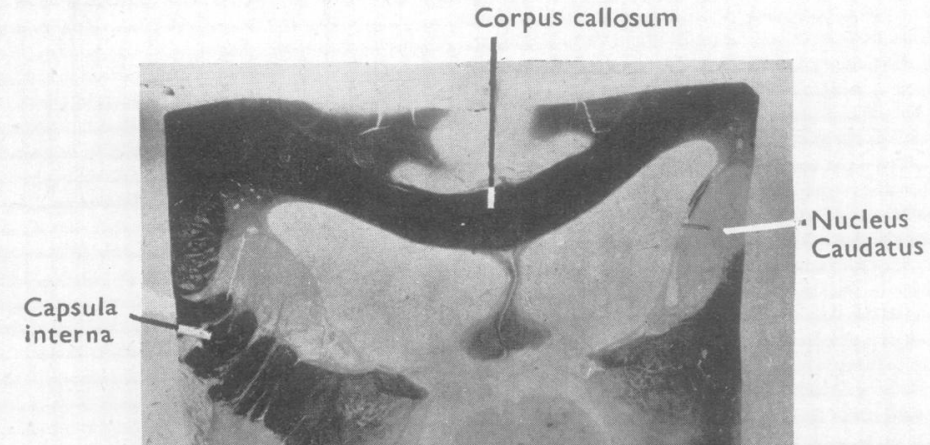

Thalamus opticus
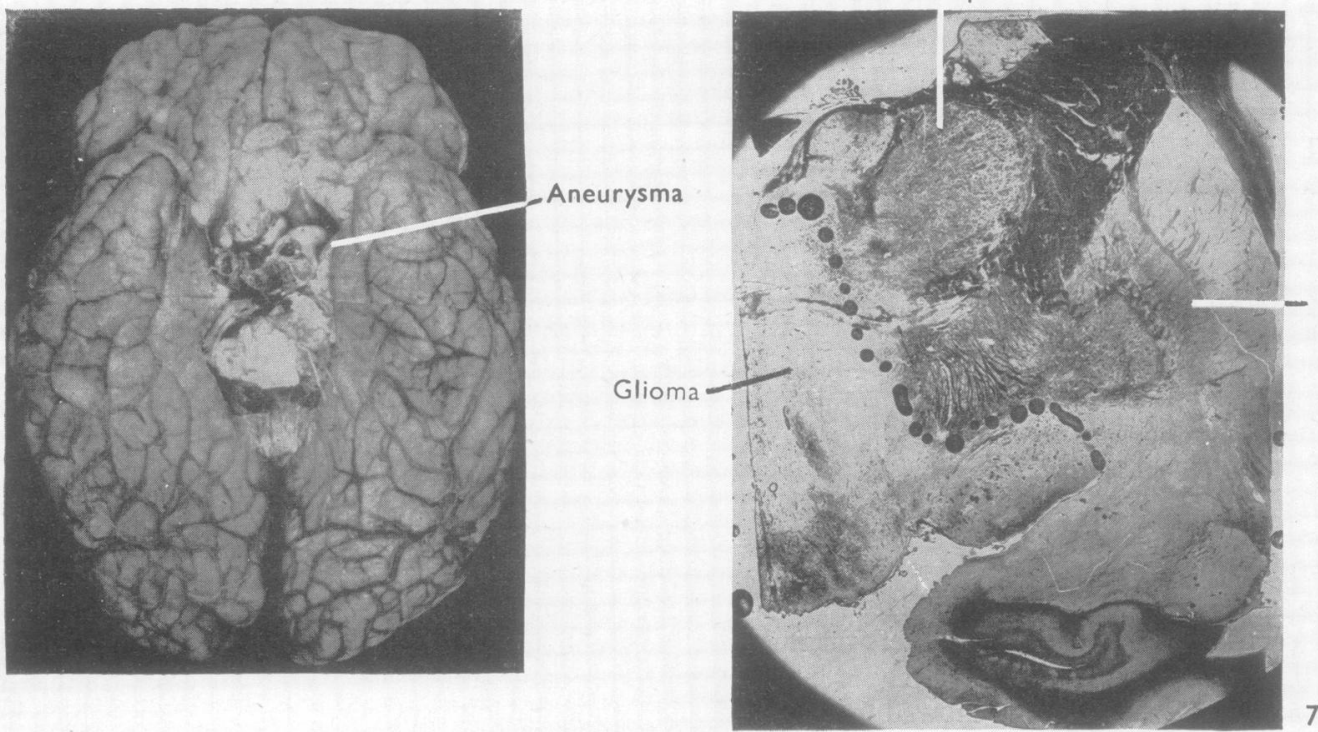

Corpus striatum 8

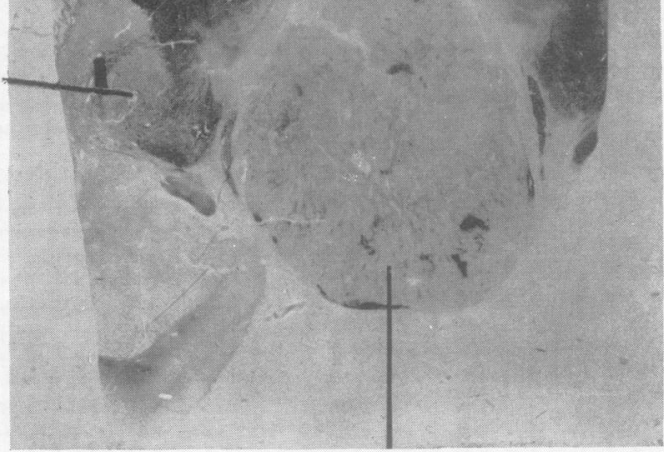

Tumour
FIG. 6.-Aneurysm of the left internal carotid artery causing acromegaly.

FIG. 7.-Circumscribed glioma in the hypothalamus associated with Korsakoff's syndrome without endocrinal symptoms.

FIG. 8.-Tumour in the hypothalamus associated with Korsakoff's syndrome. (Staining after Weigert-Pal.) 
optic nuclei does not always cause polyuria and polydipsia.

I believe that the dorso-medial, ventro-medial, and lateral nuclei of the tuber exert an important influence on vegetative functions, but up till now it is not proved that the different types of disordered metabolism correspond with lesions of distinct " centres." Hess (1948), whose method of electrical stimulation with very weak currents gives the most accurate results, also came to the conclusion that there is some localization of function in the hypothalamus but that it is not limited to circumscribed "centres."

In order to explain the contradiction between the acute experimental and the chronic clinical facts in the central vegetative nervous system one has to consider the relations in the somatic nervous system where we meet the same difficulty. An acute lesion in man, for example, causes severe disturbances in motility or in sensibility which for the most part after a time gradually disappear. The theory of diaschisis of von Monakow $(1905 ;$ 1914) which deepened our insight into cerebral localization of function, has to be applied also to the hypothalamus. Von Monakow pointed out that the various neurones are intimately connected : if one part suddenly drops out, this results in a functional reaction in all the parts of the brain linked up with the damaged area. But this reaction disappears after some weeks and only the remaining symptoms have value for localization. Many facts shown by modern neurosurgery favour this conception. Foerster (1936), for example, showed that whereas excision of small parts of the anterior central gyrus in man causes total paralysis of the corresponding extremity, motility recovers very soon. Removal of circumscribed parts of the posterior central gyrus evokes loss of cutaneous and deep sensibility in the corresponding part of the body, but again recovery takes place, and after some time the usual methods of clinical examination fail to show any diminution of sensory function. Seen in this light, the results of the experimental method and of clinical pathology do not contradict each other. They only prove that there is a refinement in the functional localization in the brain, and not least in the vegetative central nervous system. Economic reasons incite nature to follow frequently used pathways. For the security of vital functions, many fuses are placed in the central nervous system. If one of these breaks down, others redouble their activity.

At the present day, scientific investigation is focused on the hypothalamus, but vegetative functions are also represented in other parts of the brain, for example in the cerebral cortex, although here they are spread more widely. The different negative cases in hypothalamic affections point clearly in the direction of this functional luxury. Positive and negative aspects have therefore to be studied with equal care.

\section{REFERENCES}

Alpers, B. J. (1940). Ass. Res. nerv. ment. Dis., $20,725$. Aschner, B. (1929). In Hirsch, M. "Handbuch der Innern Secretion." Vol. 2. Leipzig.

Beattie, J. (1938). In "The Hypothalamus," by Le Gros Clark, Beattie, Riddoch, and Dott. Oliver and Boyd, Edinburgh.

- Brow, G. R., and Long, C. N. H. (1930). Proc. R. Soc. B., 106, 253.

Brobeck, J. R. (1946). Physiol. Rev., 26, 541.

Broers, H. (1932). " Experimenteele Diabetes Insipidus." Dissertation, University of Utrecht.

Brouwer, B. (1947). Proc. Koninklijke Nederlandsche Akademie van Wetenschappen, vol. 50.

, and Brummelkamp, R. (1948). "Le Syndrome de Puberté Précoce, Adiposité, Polydactylie, Oligophrénie et Epilepsie lors d'une Malformation Localisée dans l'Hypothalamus." Fol. Psychiat. Neurol. Neurochir. Neerlandica.

Bustamante, M. (1942). Arch. Psychiat, Nervenkr., 115, 419.

Cohn, H., and Goldstein, K. (1928). Dtsch.Z. Nervenheilk., 103, 225.

Driggs, M., and Spatz, H. (1939). Virchows Arch., 305, 567.

Fisher, C., Ingram, W. R., and Ranson, S. W. (1938). "Diabetes Insipidus and the Neuro-hormonal Control of Water-Balance." Eduard Bros. Inc., Ann Arbor, Michigan.

Francechetti, A. (1944). “L'Importance du Mésodiencéphale dans les Troubles des Fonctions Sensoriel de l'Oeil etc." Confinia Neurol, vol. 6.

Foerster, O. (1936). "Symptomatologie der Erkrankungen des Grosshirns." Handb. Neurol. (Bumke und Foerster), vol. 6.

Gagel, O. (1936) Ibid.

Gamper, E. (1928). Dtsch. Z. Nervenheilk., 102, 122.

Harris, G. W. (1948). Proc. R. Soc. Med., 41, 661.

Hess, W. R., and Brügger, M. (1943). Helv. Physiol. Pharm. Acta, 1, 511.

- (1943). Der Nervenarzt, 16, 57.

(1948). "Die funktionelle Organisation des Vegetativen Nervensystems." Monograph. B. Schwabe, Basel.

Krabbe, K. H. (1923). Endocrinology, 7, 379.

Lange, C. de (1943). Ann. Paediatr., 161, 113.

Le Gros Clark, W. E. (1938). In "The Hypothalamus," by Le Gros Clark, Beattie, Riddoch, and Dott. Oliver and Boyd, Edinburgh.

Lhermitte, J., de Ajuriaguerra, and Hecaen, H. (1942). L'Encéphale, 35, 49.

Long, C. N. H. (1940). Ass. Res. nerv. ment. Dis., 20, 486. Manschot, W. A. (1940). "Over Progeronanie (Progeria van Gilford)." Dissertation. Amsterdam.

Monakow, C. von (1905). " Gehirnpathologie." Vienna. (1914). "Die Lokalisation im Grosshirn und der Abbau der Funktion durch kortikale Herde." J. F. Bergmann, Wiesbaden.

Ranson, S. W. (1940). Ass. Res. nerv. ment. Dis., 20, 342.

Riddoch, G. (1938). In "The Hypothalamus," by Le Gros Clark, Beattie, Riddoch, and Dott. Oliver and Boyd, Edinburgh.

Roussy, G., Kourilsky, R., and Mosinger, M. (1946). Rev. Neurologique, 78, 313.

Thauer, R. (1939). Ergenbnisse der Physiologie, 41, 607. 